\title{
A atenção na cognição inventiva e no teatro
}

\section{The role of attention on theatre and inventive cognition}

Sandra Meyer Nunes ${ }^{1}$
Tatiani Borga ${ }^{2}$ 


\section{Resumo}

O artigo possui como foco a atenção, com apontamentos sobre o estudo de seu surgimento na filosofia e sua influência na psicologia moderna e no teatro. Por ser um conceito multidisciplinar, a atenção se encontra em vários campos de estudo, inclusive na arte, permitindo assim uma discussão sobre o mundo em que vivemos. Em tempos em que a quantidade de estímulos acaba por bombardear-nos de informações, o artigo trará alguns conceitos que convergem para o estudo da atenção em meio à tantas interferências. As referências para este estudo se encontram em publicações no campo da Educação, da Psicologia e do Teatro. $O$ presente estudo propõe uma reflexão sobre a noção de atenção utilizada no método de aprendizagem e na cognição inventiva proposta por Virginia Kastrup, bem como a atenção no treinamento do ator/bailarino e na recepção do espectador. Relata ainda algumas práticas de atenção no teatro e na dança realizadas no Grupo de pesquisa $O$ corpo-mente em Cena (PPGT/UDESC).

Palavras-Chave: Atenção. Cognição inventiva. Atenção no teatro. Atenção do ator.

\section{Abstract}

The focus of this article is the study of attention with a brief review of the early studies in the field of philosophy and their influence on modern psychology and theatre theories. Known a as multidisciplinary concept, attention can be found in different fields of study, including art which allows a rich discussion about the world we live especially in current times when we receive a massive amount of electronic and media information. This article will discuss some of the approaches which converge for the study of attention in such contexts. The main references came from the fields of education, psychology and theatre. We will focus on the concept of attention used on Virginia Kastrup's learning and inventive cognition method, as well as the role of attention on the dancer/actor's training and also on the spectators reception. It also reports some practices of attention in the theater and dance performed by The body-mind in scene research group (PPGT/UDESC).

Keywords: Attention. Inventive cognition. Attention in the theater. Actor's attention.

ISSN: $1808-3129$

${ }^{1}$ Orientadora do Departamento de Artes Cênicas - sandra.nunes@udesc.com.br

${ }^{2}$ Acadêmica do Curso de Licenciatura e Bacharelado em Teatro - CEART - bolsista PROBIC/UDESC 


\section{Introdução}

Neste artigo proponho levantar questões sobre um potente assunto no atual momento em que vivemos: a atenção. Para isso, buscarei um recorte sobre o estudo da atenção envolvendo o momento em que aparece como questão na filosofia e na psicologia até seu desenvolvimento nos dias atuais. A referência da atenção no campo da psicologia será voltada à cognição como aprendizagem, baseadas na noção de atenção na cognição inventiva de Virgínia Kastrup ${ }^{1}$. As reflexões acerca da atenção no Teatro serão endereçadas a uma compreensão de como importantes teóricos e diretores utilizaram e utilizam o estudo atenção, tanto para a preparação do ator quanto para a recepção do espectador.

De acordo com Leonel Martins Carneiro² (2015), a atenção tem sua origem em escritos como os de Platão, Aristóteles, Lucrécio e Santo Agostinho. No latim, a palavra attentio possui a mesma origem da palavra tentio, que significa tensão. Esta, como ele esclarece, possui o sentido de "voltar os esforços mentais para a compreensão de algo" (2015, p. 5). Segundo Carneiro, a evolução deste conceito caminha simultaneamente com o desenvolvimento da mente humana e é possível observar que, na filosofia, as tradições de Platão e Aristóteles são as mais influentes no que se refere ao estudo da atenção. Platão estabelece uma atenção dualista, na qual a operação é feita pela mente utilizando os mecanismos sensitivos do corpo, ou seja, um processo puramente mental. Assim, ele descarta a possibilidade de fatores biológicos causarem interferência no processo cognitivo. Já Aristóteles coloca o ser humano ligado com o meio, não dissociando o corpo e a mente e coloca o corpo totalmente influenciado pelo ambiente em que vive. Além disso, a teoria aristotélica denomina dois tipos de atenção: focalização da atenção e cegueira atencional, o que posteriormente a ciência vai chamar de atenção voluntária e involuntária, respectivamente. 0 estudo da atenção do ponto de vista aristotélico foi o mais difundido, influenciando Lucrécio e Santo Agostinho. (CARNEIRO, 2015)

Segundo Carneiro (2015), o estudo da atenção foi deixado de lado nos anos de 1920 por conta do Behaviorismo, que era uma teoria que não admitia o estudo de coisas que não fossem de natureza mensurável. Entretanto, em 1945, com a Segunda Guerra Mundial o estudo da atenção voltou com força total visando a melhora da capacidade atentiva dos soldados, haja vista que a atenção era muito importante para o sistema capitalista em seu poder de contribuição para as indústrias. A partir disso, as teorias que tratavam da atenção se multiplicaram no campo das ciências cognitivas e da psicologia.

"Atenção" é um conceito multidisciplinar, visto que abrange várias áreas do conhecimento como filosofia, biologia, ciências e artes. Portanto, permite uma melhor compreensão do mundo em que vivemos (CARNEIRO, 2015). É importante compreender a atenção em nosso presente e no modo como ela está sendo tratada, principalmente no que diz respeito aos milhares de estímulos que recebemos diariamente

${ }^{1}$ Doutora em Psicologia Clínica pela Pontifica Universidade Católica de São Paulo (1997), pós-doutora no CNRS em Paris (2002) e CNAM Paris (2010). Atualmente é Professora Associado da Universidade Federal do Rio de Janeiro e faz publicações em revistas de Psicologia. Possui experiência na área da Psicologia com ênfase na Psicologia Cognitiva.

${ }^{2}$ Ator, diretor, produtor, cenógrafo professor e autor do livro $A$ atenção nas teorias do teatro do século XX: De Stanislavsi à Lehmann, o qual foi uma importante fonte que utilizei para nortear este trabalho. 
e, consequentemente, à falta de atenção decorrente desta multidirecionalidade. Embora seja um campo instável, é exatamente nesse lugar conflituoso que se encontra uma potencialidade para análises e teorias. De acordo com Virgínia Kastrup, "A atualidade não revela um domínio estável e formas instruídas, nem a resultante de uma sucessão linear de eventos, mas um campo instável, do qual das transformações fazem parte." (2008, p.94).

\section{As modulações da atenção}

Em uma época na qual muito de nossa capacidade atentiva é exigida por conta de inúmeros estímulos, os estudos da psicologia e filosofia comprovam que a atenção vem se ampliando e ultrapassando as barreiras para além do ato de "prestar atenção". Sobre isso, Kastrup afirma que "o prestar atenção é apenas um dos atos de um processo complexo, que inclui modulações da cognição e da própria intencionalidade da consciência" (2004, p.171)

Sendo assim, Kastrup coloca o funcionamento da atenção como um processo que não é único e homogêneo. A intencionalidade está relacionada com o sujeito -objeto, em que a atenção opera "mutações que modificam a estrutura atencional da consciência" (2012, p.37). De acordo com o pensamento de Kastrup, a atenção não se valida apenas quando há foco, pois acredita também que a distração pode contribuir para a aprendizagem, já que esta inclui experiências pré-egóicas e não possui o sujeito como o centro do processo. Ou seja, a atenção não é condicionada somente quando há intenção, mas o não "prestar atenção" também é um tipo de atenção, o que diferencia é que não há o foco no objeto como uma finalidade.

O estudo da atenção revela a sua dimensão de variação e modulação da intencionalidade de consciência, a qual permite uma abertura para o mundo que varie em clareza e distinção (KASTRUP, 2012). De acordo com Kastrup, a atenção é passageira quando se busca aceleradamente a novidade. Ou seja, a chamada distração pode ser considerada uma mudança constante de foco de atenção. O ponto é: como redefinir o ato de prestar atenção, já que a atenção é necessária na realização de tarefas?

Kastrup dialoga em seu trabalho com Nathalie Depraz ${ }^{3}$, Francisco Varela ${ }^{4}$ e Pierre Vermersch ${ }^{5}$ (2002; 2003), os quais contribuem com o estudo da atenção a partir do conceito de devir-consciente, que é o "ato de tornar explícito, claro e intuitivo algo que nos habitava de modo pré-reflexivo" (2004, p.163). A inspiração dos autores acima vem da époché ou método da redução fenomenológica de $\mathrm{E}$. Husserl. O método da redução contribui para a aprendizagem da atenção do ponto de vista da cognição inventiva, envolvendo a suspensão da atitude natural que realiza juízos sobre o mundo. A redução é composta por três atos: suspensão, redireção e deixar vir. A primeira é a suspensão da atitude natural interrompendo o fluxo cognitivo habitual, podendo ser provocada pela experiência com a arte.

[...] a experiência estética serve para revelar o exercício de uma atenção distinta

${ }^{3}$ Professora do departamento de Filosofia da Université de la Sorbonne - Paris IV.

${ }^{4}$ Biólogo e filósofo chileno. Escreveu sobre sistemas vivos e cognição: autonomia e modelos lógicos. Autor do livro "Árvore do conhecimento".

${ }^{5}$ Psicólogo e psicoterapeuta francês, apoia o raciocínio lógico. 
daquela envolvida na realização de tarefas. A arte mobiliza e desenvolve, em sua aprendizagem, uma atitude atencional ao mesmo tempo concentrada e aberta. (KASTRUP, 2004, p. 166)

Como citado acima, a atenção opera modulações na intenção de acordo com o sujeito-objeto. $\mathrm{Na}$ arte, essa relação ampla se mostra clara por ser uma atenção sem um foco estabelecido mas concentrada em realizar a tarefa. Isso é causado pela suspensão, que "prepara a atenção para o encontro com a virtualidade que nos habita [...] e opera num nível zero de intencionalidade, acionando uma concentração sem foco e aberta ao presente" (2004, p.172). Trata-se de um abandono temporário de significação prévia do mundo para uma abertura ao ato "de deixar vir (letting go)" (2012, p.38). O ato de suspensão possibilita a redireção, na qual a atenção é voltada do exterior para o interior; com isso, não existe lugar para pensamentos ou reflexões. Associo isso à prática de meditação, na qual um dos princípios é não permitir que os pensamentos afetem o dado momento, mesmo sabendo que eles existem ${ }^{6}$. Já o deixar vir é uma concentração aberta, que não possui intencionalidade de foco. Com esses três elementos da redução, os quais consistem em mudar em relação com a atitude natural, a autora os coloca numa dimensão paradoxal: "tensionar para soltar, fechar para abrir, concentrar para deixar vir" (2004, p.173).

\begin{abstract}
O mecanismo circular da aprendizagem aponta que a atenção é ao mesmo tempo condição e efeito de um processo de aprendizagem. Entretanto, mais importante do que o problema da atenção que participa de um processo de aprendizagem é o problema do aprendizado da própria atenção, tanto em seu caráter de modulação de foco quanto de concentração aberta. (KASTRUP, 2004, p.173)
\end{abstract}

Dentro desse mecanismo da atenção como condição e efeito de um processo, ela é colocada pela autora em diversos funcionamentos como: seletivo ou flutuante, focado ou desfocado, concentrado ou disperso, voluntário ou involuntário. De acordo com Kastrup, para melhor compreensão das novas formas de viver, "é preciso afirmar o presente como movimento de virtualização das formas cognitivas construídas" (2008, p.99). O ponto está em como o presente é capaz de promover rachaduras nos fragmentos históricos. Mais do que isso, a atenção se transformou numa busca de informação para um encontro com a potencialidade de si. E o desenvolvimento cognitivo não está ligado somente com um progresso, mas também com um devir.

\title{
A atenção no trabalho do ator
}

As publicações que falam da atenção no campo da arte, mais precisamente no teatro são escassas. É importante não confundi-la com "estados de atenção", que diz respeito à presença do intérprete. Carneiro (2015) traz o alemão Hugo Münsterberg como o pioneiro nos estudos da atenção nas artes, em 1916. Não só estudioso, mas também amante do cinema, Münsterberg escreve o livro The Photoplay: a Psychological Study e compõe a primeira teoria científica sobre essa arte. Segundo Carnei-

${ }^{6}$ Iniciei a prática de meditação com aulas regulares de Yoga, fazendo meditação guiada. Posteriormente comecei a meditar sozinha, o que me proporciona mais discernimento sobre meu próprio corpo. Minha professora de Yoga contribuiu para a minha prática quando falou que meditação não é "não pensar em nada", mas não deixar que os pensamentos tomem conta da nossa mente naquele momento. 
ro, dentre as pesquisas de Münsterberg que influenciaram o cinema, destacam-se as técnicas de close-up, montagem e 3D (três dimensões). (CARNEIRO, 2015, p.14) Sendo assim, Münsterberg abriu caminho para pensar na primeira análise sobre os mecanismos que são ativados quando o acontecimento cênico atravessa a mente do expectador. A concepção de mente de Hugo Munsterberg parece atual, pois "para ele, não somos regidos apenas por fatores biológicos ou sociais, mas por uma mistura dos dois, que é o que nos guia em nossa experiência diária" (CARNEIRO, 2015, p.15) Portanto, no cinema, o diretor precisa da tecnologia, mas é preciso também que o espectador seja capaz de dialogar com o que acontece na tela e em suas experiências anteriores, de maneira sensível ou inteligível.

Carneiro (2015) afirma que Münsterberg possui uma visão muito interessante sobre o campo da atenção, pois denomina como nossa capacidade de percepção o que é controlado pela relação da atenção e a desatenção. A primeira está ligada ao consciente, sendo uma memória explícita como definem os neurologistas, ou atenção voluntária como é comumente conhecida. Ou seja, esta acontece quando nos aproximamos de algo com a intenção de focalização e aceitamos os estímulos do ambiente apenas até onde isso contribui para a busca do objetivo. Já a desatenção tem relação com as percepções do ambiente percebidas pelo inconsciente, chamada de memória implícita ou atenção involuntária. Nesta, a atenção é envolvida pelos fatores externos. Dialogando com Münsterberg, Carneiro propõe "a conceituação da atenção como uma organização do corpo-mente em benefício de um determinado estímulo e em detrimento de outro" (2015, p.18).

Embora as diferenças entre a arte cinematográfica e o palco sejam inúmeras, desde sua linguagem até o modo de execução, se faz possível fazer um paralelo entre o cinema e teatro: em ambos, nossa atenção é diretamente conduzida pelos acontecimentos. Portanto, os diretores de um espetáculo, seja teatro ou dança, precisam ter consciência para qual lugar a atenção do espectador está sendo conduzida. Isso inclui estar ciente do seu poder de direcionar a obra para pontos centrais afim de focalizar o olhar do público. Essa atenção pode ser totalmente manuseada com sons, luzes e objetos incomuns, havendo a necessidade de saber quando fazê-lo. Assim, possibilita que o processo de significação da peça alcance uma maior potência através do deixar-vir do espectador, como afirma Kastrup (2008).

No que se refere à cena teatral e ao trabalho de grandes diretores que trabaIham a atenção, o primeiro a ser lembrado é Konstantin Stanislavski (1863-1938), diretor russo que foi um dos primeiros a sistematizar o trabalho do ator no século XX. Para ele, a atenção tem papel central no treinamento do ator, que segundo Carneiro (2015) "deve ser capaz de mobilizar o seu subconsciente a partir de dispositivos acessados conscientemente, ou seja, de forma indireta" (p.23). Stanislavski (1964) visava uma criação orgânica da personagem através do método da experiência, no qual acessaria seu dispositivo de vivências e acreditava no inconsciente como fonte de criação. Numa análise da ordem de conteúdos no treinamento proposto por Stanislavski (1964), estão: atenção, imaginação, ação e relaxamento. A respeito da atenção, o desafio a ser colocado é que o ator se concentre em seu personagem e no palco, não na plateia. Segundo Stanislavski: 
Para fugir do auditório vocês têm de ficar interessados em alguma coisa no palco! [...] O ator deve ter um ponto de atenção e esse ponto de atenção não pode estar no auditório. (STANISLAVSKI, 1964, p. 102)

Stanislavski acreditava que, uma vez a atenção dirigida a um objeto em cena, despertaria ainda mais os olhares da plateia, pois "os olhos do ator que olha para um objeto e o vê atraem a atenção do espectador e por isso mesmo indicam-lhe o que ele deve olhar" (1964, p. 105). Segundo o diretor russo, quando um objeto é observado intensivamente, desperta o desejo de fazer alguma coisa com ele e, assim, intensifica a observação do mesmo. Caso o olhar dos atores tivesse vago, isso daria margem para a atenção do espectador se desviar do palco. Sendo assim, atenção e ação se entrelaçam. De acordo com Carneiro (2015), Stanislavski colocava em foco a diferença da atenção utilizada no treinamento e na atuação. No treinamento, a atenção voluntaria é treinada separada da ação e imaginação. Já no palco, a atenção é dominada pela força do hábito, se unindo à ação e imaginação. Segundo Stanislavski:

Para agarrar firmemente o nosso objetivo quando representamos, é preciso um outro tipo de atenção, que provoque uma reação emocional. Temos de ter alguma coisa que nos interesse, no objeto da nossa atenção, algo que sirva para por em movimento toda a nossa aparelhagem criadora. (STANISLAVSKI, 1964, p.115)

De acordo com Carneiro (2015), Stanislavski acreditava que atenção do ator é sempre voluntária e visa o hábito através do treinamento. Para o diretor, a situação teatral ideal seria uma atenção involuntária do público, equivalente a uma abertura sensorial na qual ele se deixa levar pelo acontecimento. Assim, a dimensão de ilusão se perde e permite a identificação com a personagem, uma característica forte do teatro dramático.

Assim como Stanislavski, no teatro épico de Bertold Brecht também se observa o foco no espectador. Entretanto, a grande diferença entre os dois é que Brecht, o pai do teatro político, desejava que o teatro fosse capaz de dialogar com as conquistas científicas do século XX para se comunicar com seu público. Brecht (1967) acredita que os recursos cênicos devem chamar a atenção do público, mas não chocá-los, pois quando existem muitos choques de atenção o espectador acaba imergindo na dramaticidade, impedindo-o de qualquer possibilidade de reflexão. Aqui se mostra claramente a diferença em relação à Stanislavski, pois Brecht defende um teatro que permita a capacidade reflexiva. A posição crítica do espectador em relação à peça se devia muito ao distanciamento que Brecht trabalhava em seus personagens, pois "além de não tentar induzir o público a qualquer espécie de transe, o ator não deve também se colocar em transe" (BRECHT, 1967, p.118). Isso era possível porque Brecht induzia o ator a mostrar apenas a sua personagem, e não vivê-la.

Brecht não promovia a ilusão em sua cena, por isso deixava claro os recursos utilizados. Ao contrário do teatro dramático que se utiliza de choques para chamar atenção no público, Brecht o fazia através do estranhamento (CARNEIRO, 2015). Este acontece quando há uma quebra de expectativa, no qual o desconhecido prende a atenção do espectador permitindo que a reflexão aconteça e, consequentemente, a atenção involuntária seja ativada. Trazendo novamente a perspectiva de Kastrup, esse 
pensamento se completa no deixar vir, que é uma concentração aberta e despida de foco. Essa capacidade torna o espaço teatral de Brecht um lugar de discussão e reflexão do mundo em que vivemos.

\section{Outros pontos de vista sobre Atenção}

Anne Bogart é diretora e professora de direção teatral na Universidade de Columbia, e mostra sua importância para pensar a atenção no teatro, pois utiliza da técnica do Viewpoints ${ }^{7}$, que são conceitos ou procedimentos de improvisação utilizados para a prática de criação em artes cênicas. De acordo com Meyer (2014), o Viewpoints chegou ao Brasil no fim dos anos 1990 e se incorporou em práticas de direção e processos de improvisação e composição de muitas companhias de teatro e dança. Meyer (2014) entende que Bogart utiliza um movimento de diferenciação de si com o outro, permitindo que os Viewpoints não se tornem "o que a diretora menos deseja: a estagnação enquanto modelo de um fazer teatral" (MEYER, 2014, p.5).

Em "Seis coisas que eu sei sobre o treinamento de atores" (2009 in: Urdimento), Bogart faz um guia de seis requisitos para o treinamento de atores. Embora a atenção seja um requisito, ela está presente em todas as outras, que são: Atitude; Atenção; Violência necessária; Controle físico e expansão das emoções; Desequilíbrio e Desorientação; Interesse. A Atitude diz respeito a disponibilidade do artista, tanto na prática quanto na sala de aula. A Atenção, nesse caso, a autora se refere mais ao papel de diretor. "Atenção é uma tensão sobre o tempo." (BOGART, 2009, p. 31). Essa tensão é no sentido da escuta do outro: o diretor escuta os atores e os atores escutam uns aos outros. Assim, as coisas se mantem em movimento, pois acontecem a partir da escuta e não da força. A Violência necessária está ligada ao arriscar-se, haja vista que Bogart (2009) acredita em um paradoxo, no qual são as restrições e a exatidão que permitem a liberdade. A diretora afirma que: "Encontrar resistência, confrontar um obstáculo ou superar uma dificuldade sempre demanda criatividade e intuição" (BOGART, 2009, p.34). O Controle físico e expansão das emoções estão relacionados ao movimento, à compressão. $O$ ator precisa ter a capacidade de resistir, conter, domar e conservar a energia em si (BOGART, 2009), pois assim, ele consegue esconder do espectador o que virá a seguir, mantendo-o mais atento aos acontecimentos. Desequilíbrio e desorientação estão ligados a sair da zona de conforto para aceitar o novo, o deixar vir. O desequilíbrio permite a entrada em um novo território e o desconhecido virá com uma surpresa que requer um salto no vazio. Interesse tem a ver com o esvaziamento do corpo, como na suspensão proposta por Kastrup (2008), que é uma atenção sem foco estabelecido, mas concentrada em realizar a tarefa. Assim, é possível desfazerse do excesso de juízo de valores sobre algo. Segundo Bogart "O maior inimigo do artista é a pressuposição, que é, talvez, o oposto do interesse." (2009, p. 10).

Pode-se perceber que os seis requisitos tem a ver com a escuta. Mas "Como ensinar a escuta? Como se aprende sobre atenção?" (BOGART, 2009, p.31). Segundo

\footnotetext{
${ }^{7}$ Os Viewpoints (pontos de vista) foram criados pela coreógrafa Mary Overlie no período do movimento de dança pós-moderna norte-americana nos anos 1970 como princípios de improvisação e composição em dança. Em 1987, Anne Bogart e Tina Landau entraram em contato com o Viewpoints e desenvolveram um trabalho conjunto no campo teatral, expandindo de seis para nove Viewpoints no tempo/espaço- Gesto, Andamento, Duração, Forma, Relação Espacial, Topografia, Arquitetura e Relação Cinestésica, e que se fazem presentes até hoje na prática de vários artistas.
} 
Meyer (2014) a diretora declara que os Viewpoints permitem explorar o conceito de comunidade como a metáfora central do teatro, como um poder de ação colaborativa e não-hierárquica no mundo, e a escuta como um mecanismo essencial para uma ação clara. Ao praticar exercícios de Viewpoints no grupo de pesquisa O Corpomente em cena ${ }^{8}$, percebo um ganho de percepção, atenção e escuta. Pudemos nos inspirar em Bogart para repensar sobre o protagonismo do sujeito na ação e se abrir para o que o outro tem a oferecer. Isso nos permitiu praticar exercícios de improvisação de modo menos hierárquico e mais compartilhado, seguindo uma determinada ética do viver junto. Segundo Meyer:

\begin{abstract}
$\mathrm{Na}$ filosofia do Viewpoints, ao invés de se agir somente por impulsos e desejos próprios, o ator/bailarino é estimulado a compreender sua conduta acional em relação com o ambiente. Tornar-se mais perceptivo ao entorno, utilizando-se de tudo o que ocorre ao redor, sem incluir ou excluir algo somente por um juízo pessoal. (MEYER, 2014, p.10)
\end{abstract}

A experiência com o Viewpoints permite que expandamos nosso centro e comecemos a parar para pensar, para re-parar e ultrapassar o juízo de valores através da suspensão. Relacionando com a prática obtida através dos encontros de pesquisa como bolsista de Iniciação Científica do grupo de pesquisa O Corpo-mente em cena, trago outra importante referência na utilização da atenção no campo da dança: o método de Composição em Tempo Real (CTR) proposto pelo coreógrafo português João Fiadeiro. Assim como Bogart, Fiadeiro (2012) pensa num modo de viver juntos e alega que neste modo de relação o processo se baseia em gerir um plano comum, desarmado do "eu" e atento ao "outro". Desenvolveu juntamente com a antropóloga brasileira Fernanda Eugênio, a "Secalharidade" (2012), um modo de relação que resulta na substituição do sujeito "por uma ética de manuseamento suficiente, que transfere para o próprio ato do encontro [...] a capacidade de fornecer a medida justa, a cada vez, para o nosso posicionamento recíproco" (2012, p.62). Nessa investigação, ele busca sentido para a re-existência através da existência/resistência, mas não como um ato de colocar-se contra, e sim num ato de colocar-se com na busca por um lugar comum, mas sem ignorar a individualidade de cada um.

Tive a oportunidade de fazer uma oficina com Fiadeiro em agosto de $2015^{9} \mathrm{e}$ o tempo foi gerido através de práticas de Composição em Tempo Real. Fiadeiro alargou nossa compreensão do que é uma composição. "É um pôr-se com o outro, uma 'posição-com-posição' que é fruto da relação de si com os demais" (FIADEIRO, 2012, p. 65, grifos meus). Para isso, é preciso atenção e pausa: parar para re-parar. Propõe formular perguntas ao invés de respostas, como: o que é isto? O que tem aqui?

Criação como estigmergia: trabalho coletivo, sem sujeito e sem objeto; trabalho ilimitado de re-materialização daquilo que emerge da relação; trabalho com o que se tem a cada vez e com o que fica, com as marcas e os rastros do viver juntos. Trabalho no qual ocupamo-nos tão somente em distrairmo-nos suficientemente

\footnotetext{
${ }^{8}$ Grupo de pesquisa coordenado pela professora Dra Sandra Meyer, em que sou bolsista de Iniciação Científica, no qual estamos praticando e vivenciando experiências relativas aos estados de atenção em conjunto desde agosto de 2014. Está vinculado ao Programa de Pós-Graduação em Teatro da Universidade do Estado de Santa Catarina

${ }^{9}$ Oficina de 20 horas promovida pelo Projeto Tubo de Ensaio - Composição [Interseções + Intervenções], um dos selecionados pelo Edital RUMOS Itaú Cultural, realizada no Centro de Artes da UDESC.
} 
do Eu para ativar a atenção ao entorno e ao manusear não manipulativo dos encaixes possíveis, à calibragem fina entre o persistir e o desistir para, então, re-existir. (FIADEIRO, 2012, p. 65)

Pode-se relacionar estes modos de gerir comunidade com o processo de cognição inventiva de Virginia Kastrup (2008), que indica um acolhimento da emergência do novo. $O$ ato de distrair-se de si para ativar a atenção para o todo é como uma redireção que vem do exterior para o interior, permitindo a re-materializaçao constante daquilo que emerge, assim como propõe Fiadeiro.

\section{Reflexões finais}

Enquanto estudante de teatro, pesquisadora e atriz, reconheço a grande contribuição dos teóricos citados acima para uma melhor compreensão do estudo da atenção no campo do teatro e da dança, bem como uma não-estagnação no fazer teatral, como sugere Anne Bogart por meio dos Viewpoints.

Assim, pode-se concluir que o modelo de criação que Fiadeiro propõe é possível porque nos abstemos do controle e do protagonismo. Assim, é possível pensar na ideia de cognição inventiva proposta por Kastrup, que acolhe a emergência do novo e coloca novas questões. Ou, ainda a "serendipidade - encontrar aquilo que não se buscava [...] Encontrar aquilo que 'calhou' ou aconteceu" (FIADEIRO, 2012, p.65). Estas indicações apontam para uma reflexão sobre o ato de reparar no que há em volta, no suspender o regime de urgência e temporalidade a que somos submetidos no dia a dia e acolher o que emerge no acontecimento presente, criando condições para uma abertura ao agora. Este modo de "viver juntos" me faz ver não só como uma solução de problemas no campo do teatro, mas também como existência e invenção de si e do mundo.

Atentos a essas questões, nas práticas realizadas no Grupo de Pesquisa O Corpo-mente em cena exercitamos as relações entre teoria e a prática e tivemos a oportunidade de compartilhar um ambiente mais arejado e compartilhado, bem como compreender o grupo como um todo, respeitando, contudo a heterogeneidade do grupo. Compreendo enquanto artista a importância de pensar sobre a atenção não só no modo de viver juntos no teatro e na dança, mas enquanto posição de sujeito político perante um sistema de relações. Em tempos em que muito se fala e pouco se ouve, acredito no poder que a atenção possui nos modos de se colocar no mundo e existir, num ato de deixar vir, mais suspenso do "eu" e mais atento ao outro.

\section{Referências}

BOGART, Anne. Seis coisas que sei sobre o treinamento de atores. Urdimento: Revista de Estudos Sobre Teatro na América Latina, Florianópolis, v.12, p.29-40, dez 2009.

BRECHT, Bertolt. Pequeno Organon para o teatro. [S.I.] : [s.n], 1948.

CARNEIRO, Leonel Martins; $A$ atenção nas teorias do teatro do século XX: De Stanis- 
lavski à Lehmann. Berlin: Novas Edições Acadêmicas, 2015.

FIADEIRO, João; EUGENIO, Fernanda. Secalharidade como ética e como modo de vida: o projeto AND_Lab e a investigação das práticas de encontro e de manuseamento coletivo de viver juntos. Urdimento: Revista de Estudos Sobre Teatro na América Latina, Florianópolis, n.19, p. 61-69, nov. 2012.

KASTRUP, Virginia; TEDESCO, Silvia; PASSOS, EDUARDO. Políticas da cognição: A cognição contemporânea e a aprendizagem inventiva, Porto Alegre: Sulina, 2008.

KASTRUP, Virginia. O funcionamento da atenção no trabalho do cartógrafo. In: PASSOS, Eduardo; KASTRUP, Virgínia; ESCÓSSIA, Liana da. Pistas do método da cartografia. Pesquisa-intervenção e produção de subjetividade. Porto Alegre: Editora Sulina, 2012.

KASTRUP, Virginia: A cognição Contemporânea e a Aprendizagem Inventiva. IN: KASTRUP, Virginia; TEDESCO, Silvia; PASSOS, EDUARDO. Políticas da cognição: A cognição contemporânea e a aprendizagem inventiva, Porto Alegre: Sulina, 2008.

MEYER, Sandra. Viewpoints: Uma filosofia da praxis. Rascunhos - Caminhos da Pesquisa em Artes Cênicas: Uberlândia, v.1, n.2, p.3-15, 2014.

STANISLAVSKI, Konstantin. A preparação do ator. Rio de Janeiro: Civilização Brasileira, 1964. 